\title{
КУЛЬТУРОЛОГИЯ
}

DOI: $10.17805 /$ trudy.2015.4.10

\section{МИФ КАК ФОРМА ОБЩЕСТВЕННОГО СОЗНАНИЯ АРХАИЧЕСКОГО ЧЕЛОВЕКА}

\author{
Л. И. Колесниченко, А. В. Фиолетова \\ (Московский гуманитарный университет)
}

Аннотация: Статья посвящена раскрытию содержания понятия «миф» и характеристике этого феномена. Авторы показывают, что практически до ХІХ в. в Европе были известны и распространены только античные мифы, однако уже во второй половине ХІХ столетия, когда были фактически открыты архаические народы, обладающие специфической культурой, и когда начинает свое развитие новая наука - антропология, в поле зрения ученых попадают мифы индоевропейских народов. Выявленные впоследствии мифы народов Америки, Африки, Австралии и Океании, показали, что на определенной стадии развития мифы существовали практически у всех народов мира.

Ключевые слова: миф, мифология, мифологическое мышление, архаическая культура, синкретизм.

\section{MYTH AS A FORM OF PUBLIC CONSCIOUSNESS OF THE ARCHAIC PERSON}

\author{
L. I. Kolesnichenko, A. V. Fioletova \\ (Moscow University for the Humanities)
}

\begin{abstract}
The article deals with the content of the concept of «myth» and the characteristic of this phenomenon. Authors show that almost until 19th century European culture knew only classical mythology. It was in the second half of the 19th century that archaic peoples with their specific culture were discovered and the development of a new science of anthropology actually commenced. Since then, anthropologists started studying myths of Indo-European peoples. When the myths of the peoples of America, Africa, Australia and Oceania subsequently came under their radar revealed, it became clear that at a certain stage of development all the peoples in the world had their own myths.
\end{abstract}

Keywords: myth, mythology, mythological thinking, archaic culture, syncretism.

Миф (от греч. mythos - 'слово', 'сказание', 'предание') часто определяют как сказание, воспроизводящее в вербальной форме архаические верования древних (и современных первобытных) народов, их религиозномистические представления опроисхождении Космоса, явлениях природы 
и событиях социальной жизни, деяниях богов, героев, демонов, «духов» и т. д. (Философия..., 2004: 584).

Однако древние люди рассматривали миф как достоверность, очевидность, которая не нуждается ни в каких доказательствах и которая не всегда представляет собой завершенный нарратив. Само сознание древних носило мифологический характер. Это связано с тем, что мир наших далеких предков в значительной степени отличался от современного, и знание об этом мире, будучи, с одной стороны, ограниченным, с другой - гораздо более широким, носило не рациональный, а эмоциональнорелигиозный характер. Сегодня представление об этом мире можно получить только при помощи изучения следов первобытной мифологии в фольклоре современных народов, а также у народов, сохраняющих архаический характер культуры - у некоторых африканских племен, обитателей островов Океании, аборигенов Австралии, Америки, у некоторых северных народов (Кармин, 2003: 321).

Мышление древних людей, носящее мифологический характер, отличается от мышления современного человека. Это проявляется в том, что миф не отделяет объект от субъекта, предмет и обозначающий его знак, объединяет пространственные и временные характеристики. Для мифологического мировоззрения характерным являлся принцип партиципации, всеобщей сопричастности всего ко всему. Человек, мысливший себя в неразрывной связи со всеми остальными элементами Космоса, не выделяя себя из этого вечно длящегося и вечно возвращающегося в себя самого и повторяющегося единства, осознавал, что и образ, созданный им - это тоже он сам.

Фактически, миф, соотносясь с прошлым, объяснял одновременно настоящее и будущее. В мифе не существует различия между настоящим и прошлым - миф представляет «теперь» и «потом» как нечто одновременное. По мнению Ф. Х. Кессиди, «диалектика мифа в том и состоит, что в мифе человек “растворяет” себя в природе, сливается с ней и овладевает силами природы лишь в воображении, но вместе с тем, это овладение силами природы (пусть в фантазии), означает начало истории духа» (Кессиди, 1972: 44).

Одними из самых древних являются мифы о происхождении Солнца, Луны и звезд. Такие мифы называются солярными, лунарными и астральными. В некоторых мифах их изображают как людей, которые по той или иной причине поднялись на небо, в некоторых создание небесных светил приписывается сверхъестественному существу. Центральной группой мифов можно назвать мифы, рассказывающие о происхождении мира, вселенной и человека. Первые обозначаются, как космогонические мифы, вторые - как антропогонические. В мифах о происхождении мира 
и людей встречаются две основные идеи. В качестве первой рассматривают идею творения, в качестве второй - идею развития. Согласно первой идее, мир был создан сверхъестественным существом, по второй он проходил процесс постепенного развития из какого-то первобытного бесформенного состояния, в качестве которого могли рассматривать хаос, мрак, или же, например, воду или яйцо. К наиболее распространенным мифологическим мотивам следует также отнести мифы о чудесном рождении, о происхождении смерти.

Для первобытного общества миф представлял собой один из основных способов понимания окружающего мира. Фактически, при помощи мифа можно отразить мироощущение и миропонимание того времени. С самых ранних времен человек вынужден был осмысливать мир, который его окружает. Мифология с этой точки зрения выступает как наиболее ранняя форма мировосприятия, которая соответствует первобытному обществу. Ее можно рассматривать как первоначальную форму духовной культуры. Мифологию следует рассматривать как некоторую систему представлений человека об окружающей природной и социальной действительности, имеющих превращенный характер. Скорее всего, причины возникновения мифа связаны с общими для того уровня культурноисторического развития особенностями мышления.

В качестве главных предпосылок и одновременно, основных особенностей мифологической логики можно рассмотреть следующие: вопервых, невыделенность первобытного человека из окружающей среды, во-вторых, логическая нерасчлененность, неотделенность мышления от эмоциональной, аффекто-моторной сферы. В результате можно было наблюдать процесс наивного очеловечивания окружающего мира, следствием которого явилась всеобщая персонификация в мифах, а также значительное сопоставление природных и социальных объектов. Человек наделял природные объекты своими собственными свойствами, чувствами и ощущениями. Космос часто представляется в мифах живым великаном, из частей которого может быть создан мир, тотемические предки рисуются существами двойной - зооморфной и антропоморфной - природы и с легкостью меняют свое обличье. Точно такие же - антропоморфные - черты обретают болезни, имеющие вид чудовищ, пожирающих души. Качества и особые свойства человека выражаются через умножение простых его свойств - сила может быть выражена многорукостью, а хорошее зрение - многоглазостью и т. д. Мифологические образы являются одушевленными, персонализированными конфигурациями тех или иных метафор. Символический образ этих метафор представляет собой иное бытие того, что он представляет. Мифологическое мышление оперирует, как правило, конкретным и персональным. Сближение объектов про- 
исходит по вторичным чувственным качествам. То, что научный анализ может определить как сходство, мифологическое мировоззрение определяет как тождество.

Миф обладает целым рядом особенностей.

Время и причинность событий в мифе. Мифологическое мировоззрение отличается присущей ему заменой причинно-следственных связей прецедентом, когда происхождение предмета выдается за его сущность. Научный принцип объяснения в мифологии заменяется «началом» во времени. Объяснение устройства предмета связано с тем, как он делался, описание окружающего мира заключалось в рассказе о его происхождении. В любом типичном мифе наблюдается отделение мифологического события от настоящего времени достаточно большим промежутком времени - все события мифа относятся к неким древним временам. Такое резкое разграничение мифологического сакрального и современного профанного времени характерно даже для самых примитивных мифологических представлений. Мифическое прошлое - это не просто предшествующее время, а особая эпоха первотворения, мифическое время, предшествующее началу эмпирического времени; мифическая эпоха это эпоха первопредметов и перводействий: первого огня, первого копья, первых действий и т. д. (Мифы народов мира ..., 2008: 11).

Функции мифа. Первобытное сознание рассматривает содержание мифа как нечто реальное, оно не различает реальное и сверхъестественное. В мифе собирался коллективный практический опыт, который накапливался на протяжении жизни нескольких поколений, поэтому люди рассматривали его как надежный. Таким образом, неспособность провести различие между естественным и сверхъестественным, безразличие к противоречию, слабое развитие абстрактных понятий, чувственноконкретный характер, метафоричность, эмоциональность следует рассматривать как характерные особенности мифологического мировоззрения, которое представляло собой символическую систему, в терминах которой воспринимался и описывался окружающий мир. Мифы являются своего рода священным духовным сокровищем племени. Они связаны с традициями племени, утверждают характерную для него систему ценностей, поддерживают определенные нормы поведения. Миф как бы объясняет и санкционирует существующий в обществе и мире порядок, он так объясняет человеку его самого и окружающий мир, чтобы поддержать этот порядок (там же: 12).

Миф как одухотворение мира. Миф можно представить как продукт человеческого разума, находившегося на момент создания мифа в своем раннем детском состоянии. Развитие мифа следует рассматривать как неотъемлемую часть развития культуры. Факты ежедневного опыта у древ- 
них людей превращались в миф благодаря существованию верований в одушевление всей природы. Данное свойство человеческого разума не является случайным. Оно непосредственно связано с тем первобытным состоянием, когда человек в мельчайших подробностях окружающего его мира видит проявления личной жизни и воли. Примитивные племена воспринимают солнце, звезды, явления природы, растения и пр. как одушевленные существа, которые живут так же, как люди или животные, и так же, как люди или животные, выполняют свое предназначение (Тайлор, 2000: 55).

Некоторые исследователи отмечают связь религии и мифа. В первую очередь это обуславливается связью между мифом и ритуалом, между священной традицией и нормами социальной структуры. Большое значение в исследовании данного аспекта имеют работы Дж. Фрезера. Исследователь показывает, что анимизм, свойственный первобытным мифам, приводит к тому, что первобытные люди без всяких усилий одушевляют различные явления. Идея жизни в природе, вера в души, которые одушевляют даже те предметы, которые в понятии современного человека являются неодушевленными, представления о переселении души, вера в различных духов, которые могут передавать свои свойства различным материальным предметам, - все это проявляется в мифологии в самых разнообразных сочетаниях, позволяя говорить о нерасчлененности самых ранних форм религии у первобытных людей - анимизма и тотемизма, шаманизма и фетишизма, эманизма и магии.

Целью магии является достижение практических результатов, она руководствуется теорией и системой принципов, которые определяют тот способ, которым следует выполнять каждое действие, для того чтобы оно было эффективным. Не зря Дж. Фрезер называет ее псевдонаукой. Практически все типы магии, так или иначе, связаны с рассказами об их истории. Эти рассказы сообщают, когда и каким образом магическая формула стала известна человеку, общине и т. д. однако такую историю нельзя рассматривать как рассказ о происхождении магии. Ибо магия никогда не происходила, не изобреталась. Она существовала изначально как дополнение ко всем вещам, которые необходимы человеку для жизни, но которые неподвластны его рациональным усилиям. Любой вид магии имеет своего рода родословную. Фактически это и есть миф о магии. Миф придает магическому действу смысл и обоснованность, сливаясь с верой в действенность магии (Малиновский, 1998: 138-140).

Магии приписывается важная социальная функция. Ее интегральная культурная функция заключается в том, что она заполняет бреши в тех видах деятельности, которыми человек еще не до конца овладел. В примитивном обществе магия дает человеку возможность убедиться в 
собственной способности достижения успеха. Также она дает ему возможность использовать ментальные и материальные техники там, где не помогают его обычные навыки и знания. Таким образом, она дает человеку возможность с уверенностью выполнять его жизненно важные задачи, сохраняя самообладание и психическую целостность, в обстоятельствах, которые, не будь магии, полностью деморализовали бы его отчаяньем и тревогой, страхом и отвращением, безответной любовью и бессильной ненавистью (там же: 137).

Миф как язык. Большую роль в образовании мифа играл язык. Уже самый факт наименования таких явлений, как зима и лето, холод и жара, война и мир, добродетель и порок, давал создателю мифа возможность представлять себе эти идеи в виде наделенных свойствами личности существ. Язык не просто отражает результаты деятельности человеческого воображения, он также играет собственную роль в мифотворчестве. При создании некоторых мифических идей на первом месте была речь, и уже потом - воображение (Тайлор, 2000: 68).

Миф, в своей живой примитивной форме, представляет собой не просто пересказ тех или иных событий, он соотносится с переживаемой реальностью. Он не является чистым вымыслом, он представляет реальность, которая возникла в очень древние времена и до сих пор может влиять на окружающий мир и на самого человека (Малиновский, 1998: 99). Пониманию примитивного мифа первобытных людей в значительной помогает изучение «живых» мифов существующих примитивных народов, способствующее восприятию мифа не в качестве символического, а в качестве прямого выражения его содержания, в качестве словесного воскрешения первобытной реальности. Пересказ мифа способствует удовлетворению глубоких религиозных потребностей, он является сводом моральных и даже практических предписаний, а также средством поддержания общественной субординации. В примитивной культуре миф выполняет незаменимую функцию: он выражает, укрепляет и кодифицирует веру; он оправдывает и проводит в жизнь моральные принципы; он подтверждает действенность обряда и содержит практические правила, направляющие человека.

Благодаря этому миф можно рассматривать как существенную составную часть человеческой цивилизации, не сказку, а активную действующую силу, устав примитивной веры и нравственной мудрости. При этом мифическое повествование, объединяя в себе правовые принципы и различные обычаи, является только частью традиционной мифологии как таковой. Таким образом, сущность мифа представлена его социальной функцией, изучение которой позволяет исследовать целостную теорию социальной организации примитивного общества (там же: 115).

Миф как фольклор - миф как знание - миф как история. Природу мифа 
объясняют самые различные теории. В качестве одной из первых можно рассмотреть школу натурмифологии, в наибольшей степени развитую в Германии. Ее сторонники утверждают, что интерес первобытного человека к природным явлениям имеет теоретический, созерцательный и поэтический характер. Представители этой школы утверждают, что каждый миф обуславливается тем или иным естественным явлением, непосредственно включенным в повествование. Однако, согласия среди этих ученых относительно того, какого рода естественное явление лежит в основе большинства мифологических построений, не наблюдается (там же: 95).

Кроме натуралистической теории существует теория, которая представляет противоположную точку зрения, и рассматривает миф как пересказ подлинных событий, произошедших в прошлом. Однако рассматривание мифологии в качестве летописи является неверным подходом. Миф, являющийся сакральным преданием племени, помогает человеку, соединяя разные стороны его культурного наследия.

Б. Малиновский, проведя исследования мифов примитивных народов, пришел к выводу, что интерес примитивного человека к природе является ограниченным. В первобытных мифах символизму отводится незначительное место, а миф сам по себе представляет важную культурную силу. Поэтому, с данной точки зрения, подобное игнорирование культурной функции мифа фактически сводит его к типу фольклора, проявляемому в смешении его различных видов - сказки, легенды, саги и т. д. (там же: 96).

Миф можно рассматривать в качестве своего рода зародыша, основы всей культуры. Он не просто дал жизнь всей культуре, прошел первоначальный этап ее развития, но и продолжает жить в ней наряду с другими культурными формами. Миф является сказанием особого рода. Его можно представить в виде вымысла, который принимается за правду. Данное определение при всей его простоте содержит внутренний парадокс. Только поняв его, можно понять и сущность самого мифа. Фактически, те, кто принимает миф как правду, не увидят в нем вымысел, а те, кто принимают его как вымысел - не воспринимают его в качестве правды. То, что для одних может представиться как правда, для других будет вымыслом (Юнг, 1997).

Архетипическая природа мифа. На основании анализа древних мифов можно сделать вывод, что мифы различных народов очень сходны по своей тематике. В различных вариациях они повествуют об одном и том же: о происхождении и устройстве мироздания, небесных тел, земли, растений, животных, человека и его образа жизни - охоты, земледелия, ремесел, обрядов и ритуалов. В мифах обязательно есть фантастические описания богов, необычайных животных, загробного царства и пр.

Древние мифы не содержат описания конкретных механизмов про- 
исходящих процессов. Однако подобный интерес к такого рода подробностям свойственен научному познанию, ни никак не мифологическому. Древним людям достаточно было описания внешних появлений различных процессов. Именно такое описание содержалось в мифах. Поэтому, с другой стороны, мир древних людей выглядел ясным и понятным. На любой вопрос мифы отвечали без затруднений, и эти объяснения имели более или менее сходную форму (там же). Именно в мифологии К.-Г. Юнг обнаружил то, что впоследствии им было названо архетипами - то есть, представлениями, имеющими универсальный, а не конкретноисторический и, тем более, не культурно-опосредованный характер, и отражающими наиболее общие феномены и явления социальной, культурной, биологической жизни человека. Наиболее фундаментальными среди них стали такие архетипы, как Герой, Отец, Учитель, Жертва, Бой, Сокровище, Восхождение, Путь, Тень и т. д. и т. п. Все эти архетипы нашли свое воплощение в мифах и в мифологических представлениях, которые имели образный характер и были предельно эмоционально насыщены.

Таким образом, несмотря на то, что современные исследователи до сих пор расходятся во взглядах на сущность и природу мифологии, сам факт того, что мифология и миф как ее законченное вербализированное построение изучаются в разных аспектах религиоведами, этнографами, философами, лингвистами, историками культуры и т. д., подтверждает значимость этого явления. Более того, мифология существует и в современной культуре, отражая те аспекты реальности, которые не могут быть охвачены научным рационализированным знанием. Именно поэтому мифология требует своего изучения как феномен, актуальный не только для архаической культуры, но и для современной.

\section{СПИСОК ЛИТЕРАТУРЫ}

Кармин, А. С. (2003) Культурология. СПб. : Лань.

Кессиди, Ф. Х. (1972) От мифа к логосу. М. : Мысль.

Малиновский, Б. (1998) Магия, наука и религия. М. : Реффл-Бук.

Мифы народов мира. Энциклопедия (2008) / гл. ред. С. А. Токарев. М. : Советская энциклопедия.

Тайлор, Э. Б. (2000) Миф и обряд. Смоленск : Русич.

Юнг, К. Г. (1997) Душа и миф. Шесть архетипов. Киев ; М.

Философия : Энциклопедический словарь (2004) / под ред. А. А. Ивина. М. : Гардарики.

Колесниченко Лариса Ивановна - кандидат педагогических наук, доцент, доцент кафедры философии, культурологии и политологии Московского гуманитарного университета. Адрес: 111395, Россия, г. Москва, 
ул. Юности, д. 5. Тел.: +7 (499) 374-51-81. Эл. адрес: livkolesn@yandex.ru Kolesnichenko Larisa Ivanovna, Candidate of Pedagogy, Associate Professor, Department of philosophy, culturology and politology, Moscow University for the Humanities. Postal address: 5 Yunosti St., 111395 Moscow, Russian Federation. Tel.: +7 (499) 374-51-81.E-mail: livkolesn@yandex.ru

Фиолетова Анастасия Владимировна - выпускница факультета культурологии и искусства Московского гуманитарного университета. Адрес: 111395, Россия, г. Москва, ул. Юности, д. 5. Тел.: +7 (499) 374-51-81. Эл. адрес: livkolesn@yandex.ru. Научный руководитель - к. пед. н., доц. Л. И. Колесничено.

Fioletova Anastasia Vladimirovna, Graduate, Faculty of Culture and Arts, Moscow University for the Humanities. Postal address: 5 Yunosti St., 111395 Moscow, Russian Federation. Tel.: +7 (499) 374-51-81. E-mail: livkolesn@ yandex.ru. Research advisor - L.I. Kolesnichenko, Candidate of Pedagogy. 